\section{TREATMENT OF PNEUMONIA.}

To the Editor of THE LANCET.

SrR,-The methods of treatment in an ordinary case of acute croupous pneumonia, such as is related by your correspondent in last week's issue, are so numerous and varied that it is little to be wondered at that those who have not adopted, from experience or College bigotry, a special plan should be somewhat doubtful as to which course to pursue, or, having treated a case in various ways, should be doubtful as to which particular remedies the benefits are due.

The "expectant plan," often commenced with but seldom carried entirely through, is unscientific and, of course, useless. Even when a case presents itself to us too late for decided antiphlogistic treatment, we can assist nature in a favourable case by giving antimony, diaphoretics, and opium, or in a dangerous one by the administration of stimulants. It is useless ascribing the benefits to a particular line of treatment which is employed just before the crisis of the disease, because its natural history tells us at what time to expect an improvement.

In the early stage, there is little doubt in the mind of those who have properly carried it out, of the beneficial results of antiphlogistic treatment, -in sthenic cases, by venesection and leeches, with calomel, opium, and aconite or tartar-emetic, and in less robust individuals leeches, with smaller doses of calomel, opium, and the cardiac depressants. As the crisis is approaching, perhaps stimulants may be required in a severe case, but in favourable cases nothing more is required than smaller doses of the cardiac depressants, combined with opium. Practically the combination of the above cardiac depressants with ammonia or alcohol is often of advantage as this period of the disease is being passed through. After the crisis is past the opium is better left off, but the mercury should be continued, and is advantageously combined with iodide of potassium. If the signs of the local mischief do not clear up as they ought to do, large blisters over the affected part will bring about the required change.

After having tried most of the methods in vogue, I have satisfied myself that the above measures, though active at first, are followed by a milder and more favourable course of the disease. Besides being supported by the results of science, they are justified upon appeal to reason.

The circulatory depression induced by the drugs must obviously limit the inflammatory effusion, and consequently must have a favourable influence by causing less material to be afterwards cleared up. The opium relieves pain, keeps all parts at rest, and is in this sense antiphlogistic, besides having apparently some specific action upon the process of inflammation. The calomel is practically an advantage, but a theory in support of it has yet to be made. Venesection must be performed rapidly, otherwise it does not induce depression of the cardiac excitement. Stimulants during the dangerous period-that is just before the crisis-seem to have other and as important influences as their action on the heart. Space will not permit me to enlarge further, but these are some of the arguments in support of this plan.

$$
\text { I am, Sir, yours, \&c., }
$$

$$
\text { T. Fredk. Pearse, M.D. }
$$

Bramshot, Liphook, Hants, August 25th, 1879.

\section{To the Editor of THE LANCET.}

SIR,-Acute sthenic pneumonia is ushered in with one single rigor, and runs a definite course of seven days; if you can keep your patient alive until the eighth day, the prognosis is favourable. Several shivering fits are not an unusual precursor in catarrhal or broncho-pneumonia, in pneumo-pleuritis, and pneumonia with other complications; also these forms of the disease run a longer and different course to simple acute pneumonia.

In answer to Mr. Moore's question, with respect to the treatment pursued, in his interesting case published in your issue of the 23rd inst., there is not the least doubt in my mind that it was the brandy and egg which enabled his patient to surmount the crisis. A lowering treatment does not suit pneumonia. I have had lately under my care a large number of acute cases of pneumonia of both lungs, one of my patients being over eighty years of age. The treatment adopted, and which has proved successful, is to order them a mixture containing liquor ammoniæ acetatis and vinum ipecac. for the first two days, with a slop nourishing diet; the local measures being turpentine stupes or jacket linseed-meal poultices during this the period of engorgement.

On the third day, order three ounces of brandy ; on the fourth, fifth, and sixth days steadily increase the stimulants, giving it in milk and egg ; also order a draught containing two grains of quinine, to be taken every four hours. Envelop the chest in cotton-wool, which is both beneficial and comforting to the patient. The quantity of stimulant ordered must be regulated in accordance with the previous habits of your patient : begin with small quantities, increasing the dose steadily up to the seventh day. Be careful strictly to watch over the nurse; everything depends upon her. If she neglects his nourishment during the nights of the sixth and seventh days of the disease, the patient is bound to slip through your fingers, especially if previously addicted to intemperance.

I am, Sir, yours faithfully, SAMuer Benton, M.R.C.S. \& L.R.C.P.

Bennett-street, S.W., Aug. 26th, 1879.

\section{THE CIVIL SURGEONS IN THE ZULU CAMPAIGN.}

To the Editor of THE LANCET.

SIR, - With the return of the British army from Zululand comes the consideration of well-earned promotion and rewards. The valuable services rendered by civil surgeons attached to the British army during the campaign (often at the imminent risk of their own lives) cannot be rewarded byl promotion or by military honours; but, nevertheless, I trust they will not be allowed to pass without suitable recognition and reward.

The correspondents of the daily press have frequently borne testimony to the honourable devotion of several of these gentlemen in attending the wounded under fire, or when closely pressed by the Zulus; and this testimony is, I know, endorsed by despatches and official reports sent to the War Office. In the London Gazette of August 21st there is a despatch from the renowned Colonel Buller, in which he says, "Throughout the operations the sick and wounded of the Mounted Corps have had the advantage of the services of Civil Surgeons Connolly and Jolly. These two gentlemen have been alike remarkable for the readiness with which they have treated wounded men under fire, and for the kindness and attention they have paid to them in camp. During the retreat from Hlobana Mountain, on March 28th, these two gentlemen not only remained with the rearguard to treat wounded, but when not so employed greatly assisted the rearguard, using the rifles of the wounded."

By inserting this note in your next issue, you will probably be the means of ensuring

August 28th, 1879. HoNOUR To WHOM HoNour is DUE.

\section{HAMATINURIA \\ To the Editor of THE LANCET.}

SIR,-The interesting lecture on hæmatinuria, in your issue of August 30th, by Dr. Charteris, has induced me to send you the particulars of the following case :-On May 3rd last a young man was sent round to me by our local chemist. He complained that his water was not quite right, and on his passing some at my request $I$ was quite startled to find that it was of a very dark port-wine colour. I found, however, that there was no blood actually present, but that the darkening was due to the hæmatin. The urine coagulated slightly on the addition of nitric acid and heat. The patient complained of an aching sensation in the back, and said he had had several slight shivering fits. He had been exposed to cold all day before the attack came on. I may mention that his occupation is that of clerk to a shipping firm, and that he is a good deal exposed to cold and river air, so that malaria cannot be quite excluded, though he has never had any other symptoms of it. He had also had a good deal of worry of a domestic nature just before his seizure. He is 